\title{
PENDAMPINGAN PENYUSUNAN DOKUMEN RENCANA PEMBANGUNAN JANGKA MENENGAH DESA
}

\author{
Sri Retno Indrastanti ${ }^{1}$, Andy Dwi Bayu ${ }^{1}$, Nursiam ${ }^{1}$, \\ Shinta Permata Sari ${ }^{1}$, Wafiatun Mukharomah². \\ ${ }^{1}$ Jurusan Akuntansi-Fakultas Ekonomi \\ ${ }^{2}$ Jurusan Manajemen-Fakultas Ekonomi \\ Universitas Muhammadiyah Surakarta
}

\begin{abstract}
The aimed of this community service activity is to increase understanding of the village stakeholders, members of the BPD and community representatives in the village of Makamhaji, Sub District of Kartasura, District of Sukoharjo about the formulation of the Village Medium Development Planning (RPJMDesa) Document, this activity also provides assistance preparation of Medium Development Plan-Village formulation so that it appears the draft Development Plan-Village Makamhaji accordance with the Regulation of the Minister of Home Affair (MoHA) number 37 and 66 in the Year 2007.

The methods used in these activities include training activities, discussions and document preparation assistance, the Village Development Plan implemented which directly implemented in the Village of Makamhaji. Training was conducted over 2 days at the Village Makamhaji, which was attended by 23 participants and technical assistance activity was conducted over 2 months after the training done to provide guidance and assistance in order to improve the preparation of the document draft of the Village Development Plan, this assistance activities take place in two places, firstly in department of Accounting FE UMS, and Village meeting room Makamhaji. As a result of training and technical assistance of planning preparation produced the draft of medium development plan document in Villages Makamhaji 2006 - 2012 which has been prepared jointly by the trainees with reference to source documents such as RPJMD Sukoharjo, Kartasura District Strategic Plan, Development Planning Consultation document (Musrenbang ) Makamhaji Village, District Kartasura Sukoharjo.
\end{abstract}

Kata kunci: RPJM desa, perencanaan, desa

\section{PENDAHULUAN}

\section{Analisis Situasi}

Pada saat ini sehubungan dengan berlakunya Otonomi daerah sebagaimana yang ditetapkan di dalam UU No.22 tahun 1999 dan telah dirubah dengan UU No.32 tahun 2004 telah merubah paradigma dalam pembangunan daerah, dimana tanggung jawab perencanaan, pelaksanaan dan monitoring diserahkan kepada daerah. UU No.32 tahun 2004 lebih mempertegas bahwa otonomi daerah tidak hanya berada pada tingkat Kabupaten/kota, tetapi juga pada tingkat desa. Pengalokasian Dana Alokasi Desa merupakan 
cerminan bahwa di tingkat desapun perlu mengurus perencanaannya sendiri, walaupun tidak sekompleks perencanaan di tingkat Kabupaten / Kota.

Bahkan didalam SEB Bappenas dan Menteri Dalam Negeri yang diterbitkan sejak tahun 2005 dan setiap tahun diperbaharui, selalu menekankan pentingnya proses partisipatif didalam proses perencanaan pembangunan daerah, dengan menyelenggarakan Musyawarah Pembangunan (Musrenbang) yang dimulai dari tingkat Desa hingga tingkat Kabupaten / Kota khususnya dalam rangka penyusunan dokumen perencanaan dan penganggaran desa mulai dari penyusunan Rencana Pembangunan Jangka Menengah Desa (RPJM-Desa), Rencana Kerja Pembangunan Desa (RKP-Desa) sampai pada penyusunan Anggaran Pendapatan dan Belanja Desa (APB-Desa).

Pada saat ini Desa Makamhaji belum dapat menyusun dokumen perencanaan tersebut yang seharusnya berdasarkan pada Peraturan Menteri Dalam Negeri Nomor 66 tahun 2007 tentang Perencanaan Pembangunan Desa yang telah diterbitkan pada tanggal 28 Nopember 2007 sudah dilaksanakan di tingkat desa.

Penyusunan RPJM-Desa dinilai sangat penting karena program dan kegiatan yang akan dilaksanakan di desa yang akan didanai oleh APBDes harus tercatat dan terprogram dalam dokumen tersebut di atas. RPJM-Desa sebagai dokumen perencanaan lima tahunan digunakan sebagai dasar dalam penyusunan RKP-Desa dan APB-Desa yang nantinya digunakan sebagai pedoman dalam pelaksanaan program dan kegiatan di tingkat desa.

Peserta pelatihan ini tergolong kategori pelaksanan strategis yaitu sebagai legislatif dan juga sebagai eksekutif di tingkat desa yang memiliki wewenang dalam penyusunan peraturan-peraturan di tingkat desa dan pelaksana program dan kegiatan di tingkat desa.

\section{Perumusan Masalah}

Belum disusunnya dokumen Rencana Pembangunan Jangka Menengah Desa (RPJM-Desa) di Desa Makamhaji, Kecamatan Kartasura Kabupaten Sukoharjo.

Permasalahan yang menjadi pokok perhatian pengabdian masyarakat ini adalah bagaimana meningkatkan pemahaman pada para pemangku kepentingan (stakeholder) khususnya pada perangkat desa, anggota BPD dan wakil masyarakat di Desa Makamhaji tentang cara-cara penyusunan dokumen RPJM-Desa Makamhaji mulai dari proses penjaringan aspirasi masyarakat dalam forum musyawarah perencanaan pembangunan desa sampai pada tersusunnya dokumen perencanaan RPJM-Desa Makamhaji sebagai dasar perencanaan pembangunan di Desa Makamhaji.

\section{Tinjauan Pustaka.}

RPJM-Desa disusun untuk menjamin keterkaitan dan konsistensi antara perencanaan, penganggaran, pelaksanaan, dan pengawasan pembangunan desa. RPJMDesa merupakan penjabaran dari visi dan misi dari Kepala Desa yang terpilih (Permendagri 37/2007 pasal 5 ayat 1).

Berdasarkan Permendagri nomor 66 tahun 2007 pasal 5 ayat 2 penyusunan RPJMDesa memiliki beberapa prinsip dasar sebagai berikut, yaitu :

a. Pemberdayaan, yaitu upaya untuk mewujudkan kemampuan dan kemandirian masyarakat dalam kehidupan bermasyarakat, berbangsa dan bernegara;

b. Partisipatif, yaitu keikutsertaan dan keterlibatan masyarakat secara aktif dalam proses pembangunan;

c. Berpihak pada masyarakat, yaitu seluruh proses pembangunan di pedesaan secara serius memberikan kesempatan yang 
seluas-luasnya bagi masyarakat, khususnya masyarakat miskin;

d. Terbuka, yaitu setiap proses tahapan perencanaan pembangunan dapat dilihat dan diketahui secara langsung oleh seluruh masyarakat desa;

e. Akuntabel, yaitu setiap proses dan tahapan-tahapan kegiatan pembangunan dapat dipertanggungjawabkan dengan benar, baik pada pemerintah di desa maupun pada masyarakat

f. Efisiensi dan efektif, yaitu pelaksanaan perencanaan kegiatan sesuai dengan potensi sumberdaya alam dan sumberdaya manusia yang tersedia,

g. Keberlanjutan, yaitu setiap proses dan tahapan kegiatan perencanaan harus berjalan secara berkelanjutan,

h. Cermat, yaitu data yang diperoleh cukup obyektif, teliti, dapat dipercaya, dan menampung aspirasi masyarakat;

i. Proses berulang, yaitu pengkajian terhadap suatu masalah/hal dilakukan secara berulang sehingga mendapatkan hasil yang terbaik;

j. Penggalian informasi, yaitu di dalam menemukan maslah dilakukan penggalian informasi melalui alat kajian keadaan desa dengan sumber informasi utama dari peserta musyawarah perencanaan.

\section{Tujuan dan Manfaat}

\section{a. Tujuan Kegiatan}

1) Meningkatkan pemahaman pada para pemangku kepentingan (stakeholder) khususnya pada perangkat desa, anggota BPD dan wakil masyarakat di Desa Makamhaji tentang cara-cara penyusunan dokumen RPJMDesa Makamhaji.

2) Menghasilkan draft dokumen Rencana Pembangunan Jangka Menengah Desa (RPJM-Desa) di Desa Makamhaji.

\section{b. Manfaat Kegiatan}

1) Meningkatnya pemahaman para pemangku kepentingan (stakeholder) khususnya pada perangkat desa, anggota BPD dan wakil masyarakat di Desa Makamhaji tentang cara-cara penyusunan dokumen RPJMDesa Makamhaji.

2) Tersusunnya draft dokumen Rencana Pembangunan Jangka Menengah Desa (RPJM-Desa) di Desa Makamhaji.

\section{METODE PELAKSANAAN}

\section{Kerangka pemecahan masalah}

Secara umum, alur pemikiran penyusunan perencanaan desa sebagai berikut:

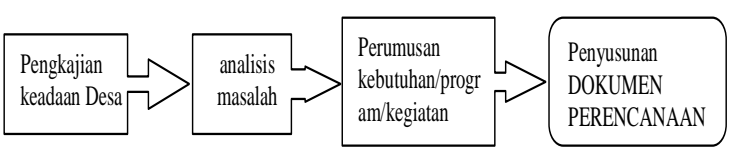

Gb. 1. Skema Penyusunan Rencana Desa

\section{Realisasi pemecahan masalah}

Evaluasi yang dilakukan di dalam pengabdian ini dilakukan pada tahap-tahap yang berbeda:

Praktik langsung, dimaksudkan untuk melatih memahami materi yang diberikan Praktik langsung ini dinilai, sehingga hasil penilaian dapat digunakan sebagai tolak ukur keberhasilan pelaksanaan pengabdian.

Keberhasilan ini apabila audience mampu:

a. Menjelaskan proses dan mekanisme penyusunan dokumen RPJM-Desa.

b. Menyusun draft dokumen RPJM-Desa.

\section{Khalayak sasaran}

Khalayak sasaran dari pengabdian masyarakat ini adalah perangkat desa, anggota BPD dan tokoh masyarakat Desa Makamhaji, Kecamatan Kartasura, Sukoharjo. Khalayak sasaran adalah orang-orang yang bertanggung jawab dalam proses pembangunan Desa Makamhaji. 
Kegiatan ini melibatkan beberapa pihak terkait:

a. Perangkat desa, anggota BPD dan wakil masyarakat di Desa Makamhaji. Dengan diselenggarakannya pengabdian masyarakat ini, diharapkan mereka dapat berperan sebagai motor penggerak di wilayahnya dalam upaya-upaya memajukan pembangunan di desanya.

b. Lembaga Penelitian dan Pengabdian Pada Masyarakat (LPPM) UMS, yang berperan selaku fasilitator dan pelaksana.

\section{Metode kegiatan}

Penyusunan Rencana Pembangunan Jangka Menengah Desa (RPJM-Des) menggunakan dasar Peraturan Pemerintah Nomor 72 Tahun 2005 tentang Desa, Peraturan Menteri Dalam Negeri Nomor 37 Tahun 2007 tentang Pedoman Pengelolaan Keuangan Desa, dan Peraturan Menteri Dalam Negeri Nomor 66 Tahun 2007 tentang Perencanaan Pembangunan Desa.

a. Pelatihan

Materi disampaikan dalam bentuk pelatihan yaitu penyusunan dokumen RPJM-desa bagi Perangkat desa, anggota BPD dan wakil masyarakat di Desa Makamhaji, yaitu:

1) Aspek regulasi dalam perencanaan desa

2) Fungsi RPJM-Desa sebagai pedoman dalam proses pembangunan desa.

3) Partisipasi masyarakat dalam penyusunan dokumen RPJM-Desa.

4) Proses penyusunan dokumen RPJMDesa.

b. Ceramah

Ceramah diberikan di dalam menyampaikan materi dan dilakukan oleh pelaksana pengabdian.

c. Diskusi

Selain dengan ceramah, penyampaian materi juga dilakukan dengan diskusi yang melibatkan pelaksana pengabdian dan peserta pelatihan. Diskusi berkisar pada berbagai hal yang berkaitan dengan penyusunan dokumen RPJM-Desa.

d. Pendampingan

Pendampingan diberikan kepada peserta paska pelatihan dalam rangka terwujudnya dokumen Rencan Pembangunan Jangka Menengah Desa (RPJM-Desa)

e. Rencana Kegiatan

Menyediakan 1 buah laptop dan 1 LCD Viewer, jumlah peserta 20 orang dan 4 orang instruktur.

Tempat kegiatan: Gedung Pertemuan Desa Makamhaji, Kecamatan Kartasura, Kabupaten Sukoharjo.

\section{HASIL DAN PEMBAHASAN}

\section{Proses Pelaksanaan}

Berdasarkan pada Permendagri 37/ 2007 pasal 5 ayat 1, RPJM-Desa disusun untuk menjamin keterkaitan dan konsistensi antara perencanaan, penganggaran, pelaksanaan, dan pengawasan pembangunan desa. RPJM-Desa merupakan penjabaran dari visi dan misi dari Kepala Desa yang terpilih. Untuk itu Pemerintah Desa Makamhaji sebagai bagian dari Pemerintah Republik Indonesia harus mematuhi hal tersebut, untuk pelaksanaan pendampingan penyusunan dokumen tersebut diberikan tahapan sebagai berikut:

a. Tahap pelatihan

Pelatihan penyusunan RPJM-Desa Makamhaji diselenggarakan selama 2 hari yaitu pada 13 - 14 Maret 2009, Pelatihan ini melibatkan seluruh kepala urusan, anggota BPD, perwakilan masyarakat dan beberapa kepala dusun di Desa Makamhaji, Kecamatan Kartasura, Kabupaten Sukoharjo. 
Adapun materi yang disampaikan dalam pelatihan tersebut adalah sebagai berikut:

1) Aspek regulasi dalam perencanaan desa sesuai dengan Peraturan Pemerintah nomor 72 tentang Desa, Permendagri 66 tahun 2007 tentang Perencanaan Pembangunan Desa, Permendagri 37 tahun 2007 tentang Pedoman Pengelolaan Keuangan Desa, dan beberapa Peraturan Daerah Kabupaten Sukoharjo yang terkait terkait dengan Desa.

2) Fungsi RPJM-Desa sebagai pedoman dalam proses pembangunan desa, dijelaskan lebih lanjut bahwa RPJMDesa merupakan sebuah dokumen perencanaan yang sangat dibutuhkan oleh Desa Makamhaji guna membuat perencanaan jangka panjang sebagai guidelines dalam penyusunan perencanaan dan RAPBDesa Makamhaji.

3) Partisipasi masyarakat dalam penyusunan dokumen RPJM-Desa, bagaimana masyarakat dapat berpartisipasi dalam penyusunan dengan dibuktikan pada dokumen usulan kebutuhan masyarakat yang menjadi sumber dari proses penyusunan dokumen RPJM Desa. Di samping itu dijelaskan beberapa teknik partisipasi seperti tknik jaring aspirasi, teknik seleksi, teknik prioritas dan metode dalam proses partisipasi masyarakat yang meliputi: Penerapan Metode Partisipasi dalam Proses perencanaan desa, Penemu kenalan isu strategis, Identifikasi Potensi, Kelemahan, peluang dan tantangan dan Pengusul-an strategi dan Program

4) Proses penyusunan dokumen RPJMDesa, dijelaskan bahwa proses penyusunan dokumen RPJMDesa melalui beberapa proses yang lumayan banyak, dengan proses dalam bagan sebagai berikut:

Tabel 1

Proses Penyusunan Dokumen

RPJM-Desa
Adapun form-form dan alat bantu ada di lampiran.

\section{b. Tahap Pendampingan}

Pada tahap ini para peserta pelatihan akan didampingi dalam menyempurnakan penyusunan Rencana Pembangunan Jangka Menengah Desa (RPJM-Desa) Makamhaji sampai pada draft yang siap untuk disahkan menjadi Peraturan Desa Makamhaji. Pola Pendampingan dilakukan dengan langkah sebagai berikut: 
1) Setiap minggu dilakukan pengecekan terhadap progress penyusunan dokumen yang dilakukan oleh tim pelatih dan pengabdian masyarakat.

2) Membuat ruang konsultasi khusus di ruang dosen Jurusan Akuntansi FE UMS, sehingga setiap peserta pelatihan dapat langsung datang dan berkonsultasi dengan tim pengabdian masyarakat.

Pendampingan kepada masyarakat dilaksanakan selama kurun waktu 2,5 bulan dari tanggal 16 Maret sampai 30 Juni 2009.

\section{Hasil Pelaksanaan}

Sebagai hasil pelatihan dan pendampingan yang telah dilakukan dihasilkan satu draft dokumen RPJM-Desa Makamhaji Tahun 2006 - 2012 yang telah disusun bersama oleh para peserta pelatihan dengan merujuk pada dokumendokumen sumber seperti RPJMD Sukoharjo, Renstra Kecamatan Kartasura, dokumen hasil Musyawarah Perencanaan Pembangunan (Musrenbang) Desa Makamhaji, Kecamatan Kartasura, Kabupaten Sukoharjo. Untuk sistematika RPJM-Desa Makamhaji mengikuti alur sebagai berikut:

Bab I PENDAHULUAN

1.1. Latar Belakang

1.2. Maksud dan Tujuan

1.3. Landasan Hukum

Bab II GAMBARAN UMUM KONDISI DESA

2.1 Sejarah Desa

2.2 Profil Desa

Bab III VISI DAN MISI DESA

3.1. Visi Desa (mengenai keadaan yang diinginkan pada akhir periode perencanaan)

3.2. Misi Desa (mengenai upayaupaya yang akan dilaksanakan untuk mewujudkan visi.
Bab IV STRATEGI PEMBANGUNAN DESA

4.1. Permasalahan yang dihadapi Desa

4.2. Gambaran Kekuatan, dan Peluang atau Potensi yang dimiliki Desa

4.3. Perumusan Strategi Pembangunan Desa

Bab V. ARAH KEBIJAKAN KEUANGAN DESA

5.3. Arah Pengelolaan Pendapatan Desa

5.2. Arah Pengelolaan Belanja Desa

5.3. Arah Pengelolaan Pembiayaan Desa

Bab VI. KEBIJAKAN UMUM DAN PROGRAM PEMBANGUNAN DESA

6.1. Kebijakan Umum (arah/ tindakan yang diambil oleh pemerintah desa untuk mencapai tujuan)

6.2. Program:

6.2.1. Skala Desa

6.2.2. Usulan ke tingkat kecamatan (SKPD, lintas SKPD, Lintas wilayah)

\section{LAMPIRAN}

\subsection{Kegiatan}

1. Ringkasan muatan informasi dalam RPJM-Desa

2. Adapun dokumen RPJMDesa tersebut terlampir.

\section{Pembahasan}

Dalam pelaksanaan penyusunan dokumen RPJMDesa Makamhaji secara umum berjalan dengan cukup lancar, hal ini terlihat dari antusiasnya peserta dalam mengikuti proses pelatihan, dan pendampingan masyarakat, akan tetapi dalam pelaksanaan terdapat beberapa hambatan 
yang menjadi kelemahan dalam proses ini yaitu :

a. Kurangnya pemahaman para pemangku kepentingan tentang pentingnya penyusunan Dokumen RPJMDes ini, hal ini dibuktikan dengan kesulitan yang dihadapi peserta dalam mencari data di masyarakat.

b. Beragamnya tingkat pendidikan para peserta, hal ini menyebabkan tingkat serapan materi pelatihan menjadi tidak seimbang, sehingga di satu sisi ada peserta yang sudah sangat paham, sedang di sisi lain ada peserta yang kurang memahami materi yang disampaikan.

c. Adanya dominasi dari pihak tertentu yang ingin memasukkan program dan kegiatannya ke dalam RPJMDesa, sehingga membuat dokumen tersebut menjadi kurang aspiratif.

\section{SIMPULAN DAN SARAN}

\section{Simpulan}

RPJM-Desa Makamhaji tahun 2007 sampai dengan 2012 merupakan penjabaran visi misi dari Kepala Desa terpilih periode tahun 2007 sampai dengan 2012. RPJMDesa Makamhaji disusun dengan mengacu pada RPJM Daerah Kabupaten Sukoharjo dan Rencana Tata Ruang Kabupaten Sukoharjo yang terkait dengan letak dan fungsi desa Makamhaji.

RPJM-Desa Makamhaji disusun dengan tujuan:

a. Mewujudkan perencanaan pembangunan desa sesuai dengan kebutuhan masyarakat dan keadaan setempat

b. Menciptakan rasa memiliki dan tanggungjawab masyarakat terhadap program pembangunan di desa

c. Memelihara dan mengembangkan hasilhasil pembangunan di desa d Menumbuhkembangkan dan mendorong peran serta masyarakat dalam pembangunan desa.

e Adapun maksud penyusunan RPJMDesa adalah sebagai pedoman dalam penyusunan RKP-Desa.

\section{Saran}

Untuk kegiatan pengabdian lebih lanjut perlu untuk memperhatikan hal-hal sebagai berikut :

a. Memberikan pola pemahaman yang berbeda pada khalayak sasaran yang memiliki latar belakang berbeda pada sisi pendidikan.

b. Memperpanjang waktu pendampingan sehingga dokumen perencanaan secara rinci dapat diselesaikan sampai peraturan desa terwujud.

c. Mengurangi dominasi dari salah satu pihak dengan strategi dan cara tertentu sehingga obyektifitas hasil dapat tercapai.

\section{PERSANTUNAN}

Dalam pelaksanaan kegiatan pengabdian masyarakat ini kami tidak lepas dari bantuan dan bimbingan beberapa pihak. Ucapan terimakasih kami sampaikan kepada:

1. Bapak Rektor Universitas Muhammadiyah Surakarta melalui Lembaga Penelitian dan Pengabdian pada Masyarakat UMS yang telah memberikan dana sehingga kegiatan ini dapat berjalan dengan baik.

2. Pimpinan Fakultas Ekonomi yang ikut memperlancar kegiatan ini.

3. Kepala Desa Makamhaji, kecamatan Kartasura, kab Sukoharjo, beserta seluruh kepala urusan desa, anggota BPD, perwakilan masyarakat, dan kepala dusun dilingkungan desa Makamhaji yang telah berpartisipasi dan terlibat dalam pelaksanaan kegiatan masyarakat ini. 


\section{DAFTAR PUSTAKA}

Departemen Dalam Negeri. 2007. Permendagri 37 tahun 2007 tentang Pedoman Pengelolaan Keuangan Desa. Jakarta.

2007. Permendagri 66 tahun 2007 tentang Perencanaan Pembangunan Desa. Jakarta.

Pemerintah Republik Indonesia. 2005. Peraturan Pemerintah nomor 72 tentang Desa. Jakarta. Mardiasmo. 1999. Akuntansi Sektor Publik. BPFE UGM. 
